\title{
Behavioral Economics and the Psychology of Fruit and Vegetable Consumption
}

\author{
Joseph Price \\ Brigham Young University
}

Jason Riis

Harvard University

Received: June 27, 2012

Accepted: July 11, 2012 Published: December 1, 2012

doi:10.5296/jfs.v1i1.2014

URL: http://dx.doi.org/10.5296/jfs.v1i1.2014

\begin{abstract}
Behavioral economics is an emerging paradigm that challenges the assumptions and predictions of classical economics. This new paradigm emphasizes that consumers do not always make optimal use of available information nor do they always make choices and tradeoffs in a manner that optimizes their well-being. After describing some basic concepts in behavioral economics, this paper reviews the growing literature that applies these concepts to the consumption of fruits and vegetables. A toolkit to increase consumption of fruits and vegetables is developed based on an analysis of previous research. Three general kinds of tools are described: tools for 1) displays and settings, 2) incentives and prices, and 3) planning and habits.
\end{abstract}

Keywords: Fruits and vegetables, Behavioral economics, Marketing

JEL codes: D03, Q18, I18, M30 


\section{Introduction}

In many developed countries, including the United States, consumers do not eat enough fruits and vegetables (CDC, 2009). The standard policy tools of price subsidies and informational campaigns can help address this problem, but a new paradigm in economics, behavioral economics, provides a framework for devising additional policy tools.

Historically, regulatory and marketing policies in many domains have been devised using the assumptions of classical economics, whereby consumers make optimal use of available information and make choices and tradeoffs in a manner that optimizes their well-being. While it has long been recognized that these assumptions were not quite right, only in the last 15 years have economists taken seriously the possibility that there are many cases when these assumptions are substantially off the mark. Many now argue that more realistic assumptions must be made in order to make accurate forecasts, to devise effective policies, and to execute effective marketing campaigns (Orszag, 2008).

Many of these ideas have been used to understand and change eating patterns and specifically improve fruit and vegetable consumption. In what follows, these principles from behavioral economics are used to outline a set of approaches (or toolkit) that can be used to encourage increased consumption of fruits and vegetables. This toolkit applies to many kinds of consumers (e.g., children, employees, retail customers, low income individuals, etc.) in many contexts (e.g., home, school cafeterias, restaurants, supermarkets, etc.), and can be applied by many kinds of marketers and stakeholders (e.g., producers, retailers, parents, and governments).

In many cases, regulation could be considered. But in most cases, the recommendations could at least inform institutional policies where the particular institution has an interest in helping people to eat better. This is certainly the case with school and workplace cafeterias, but it is increasingly true in retail settings (restaurants and supermarkets) where industry groups, or large chains, may want to adopt some of these approaches to avoid more heavy-handed regulation in the future. This could also be the case for government aid programs like Supplemental Nutrition Assistance Program (SNAP) or Women, Infants, and Children (WIC) where administrators may be able to influence consumer behavior and retailer best practices through minor administrative or policy changes.

\section{Behavioral Economics and Psychology}

\section{Automatic and Reflective Systems}

Many economists now accept a widely held psychological theory of the human mind which characterizes two separate but interacting systems - an automatic system and a reflective system (Kahneman 2003, 2011). The automatic system makes decisions that are fast, effortless, uncontrolled, emotional, and often unconscious. By contrast, the reflective system makes decisions that are slow, effortful, controlled, deductive, and generally involve self-awareness. 
An often-seen behavior of the automatic system is the preference for default options. If people actively choose and carefully reflect on all of their decisions, then they should not be heavily influenced by whether or not a particular option happens to be the default. But people are heavily influenced by defaults, even for very important decisions. This insight has been used to develop policies that, for example, encourage higher savings rates. Choi et al. (2003) found higher rates of participation in a workplace savings plan when employees were enrolled unless they opted out, as opposed to a more traditional plan where employees were not enrolled unless they opted in. Even for important decisions like retirement savings, decisions are often governed by the automatic systems.

Not all decisions are automatic of course. In the food context, the reflective system is at play when people do things like count calories, a strategy that is effective for some dieters (at least initially). Another more general example of the reflective mind at work is seen in decisions to pre-commit to more sensible choices. When given the opportunity to do so, people often make choices that commit their future selves to better actions, because they know that their present selves have limited self-control (Thaler \& Benartzi, 2004).

\section{Non-standard Beliefs, Preferences, and Decision Making}

As acceptance of the role of automatic processes in consumer decision making has grown, economists have begun to classify and model the behaviors that result from them. DellaVigna (2009) usefully characterizes the departures from the standard (or strictly rational) consumer model into three categories: Non-standard beliefs, non-standard preferences, and non-standard decision making.

Non-standard beliefs include situations in which individuals systematically adopt opinions that are not appropriate given the available evidence. For example, people tend to be overconfident in their beliefs - that is, they hold their beliefs with more certainty than they should (Barber \&Odean, 2002; Camerer \&Lovallo 1999; Moore \& Healy 2008). The main feature of non-standard preferences is that the preference for immediate gratification is often overpowering (Thaler \& Benartzi, 2004; Ausubel 1999). Finally, non-standard decision making occurs when, for example, people use suboptimal heuristics to simplify their choices. One such heuristic is the diversification bias, whereby people choose more variety than they will actually enjoy (Simonson, 1990).

\section{Behavioral Economics Toolkit}

Table 1 summarizes the proposed toolkit. Most of the examples in this toolkit will leverage some form of the "non-standard" or "irrational" beliefs, preferences, and decision making schemes outlined by DellaVigna (2009). Others may be consistent with the standard assumptions (at least under some interpretations) but have a strong psychological element and are certainly relevant to the marketing of produce. Some tools will be new; others will just seem like common sense. The purpose here is to provide a useful organization of these tools with the context of a new model of human behavior that is becoming more widely accepted by social scientists of all types. 
Readers who are interested in a longer (and quite technical) review of behavioral economics should see DellaVigna (2009). A general audience treatment of behavioral economics is provided by Thaler and Sunstein (2008). Many of the examples in this toolkit come from food-related reviews by Just et al. (2007) and by Chandon and Wansink (2011).

\section{A. Display and Setting Tools and Policies}

\section{Prominence and Convenience}

Because people make so many choices with minimal thought or effort, making foods prominent at the point of purchase is one of the most important strategies for increasing their consumption. This is why manufacturers pay so much money in slotting fees at supermarkets. Thorndike et al. (2012) increased sales of bottled water in a hospital cafeteria $30 \%$ by simply placing bottles of water in baskets beside each food station in the cafeteria. These additional displays did not involve refrigeration, so it may not work for juice, but it certainly could work for easy to grab fruits such as apples or bananas. Wansink (2011) reports success at increasing fruit consumption at a school cafeteria by creating a prominent, well lit, attractive display; however, large scale trials have not yet been reported. Prominence may also work through menu placement. In a study using customers at a Subway restaurant, Downs et al. (2009) increased consumption of healthy sandwiches by placing them farther up on the menu.

Related to prominence is also the ease with which individuals can access these items. Cullen et al. (2003) find that parent's and children's reported accessibility of fruit, juice, and vegetables were significant predictors of the children's consumption of these foods. Wansink (2011) notes that in cafeteria settings where trays are not used, individuals are much less likely to eat vegetables as part of their meal. Since vegetables are often eaten as a side dish, if people can only carry one plate, they are more likely to forgo vegetables.

Several approaches could easily increase the prominence and convenience of fruits and vegetables in both stores and homes. For example, stores can place more fruits and vegetables at the check-out counter instead of a candy display. Parents can place fruits in an attractive and transparent bowl on the kitchen counter or place cut up vegetables in the fridge so that family members will see these items first when they go looking for a snack. In a study in workplace cafeterias, Bandoni et al. (2011) find that display of fruits and vegetables, in addition to menu planning and motivational techniques, increased fruit and vegetable consumption by over $15 \%$. These findings, in conjunction with those cited above, suggest that adults and children alike are positively influenced by the presentation and convenience of fruits and vegetables.

\section{Increase Variety}

Several studies have shown that people consume more food overall when they have more options to choose from, especially if they are allowed to choose more than one item. In a lab experiment by Bucher et al. (2011), student participants chose a greater quantity of vegetables when offered two choices of vegetables instead of one, suggesting that offering an increased variety of vegetables may result in higher rates of consumption. 
Just, Lund, and Price (2012) find similar effects in elementary school cafeterias. They find that each additional fruit or vegetable item offered increases the fraction of children who eat at least one serving of fruits and vegetables by $12 \%$. The increased use of salad bars in school cafeterias (part of Michele Obama's “Let’s Move Salad Bars to Schools” initiative) provides the opportunity to dramatically increase the variety of fruits and vegetables that children have access to during lunch. Similar efforts to provide children access to a fruit bar as part of the school breakfast program could yield similar results.

There is some evidence that variety can backfire if people can only choose one option. In one famous study (Iyengar \& Lepper, 2000), supermarket customers were more likely to purchase a jar of jam if they only had 6 flavors to choose from rather than 24. It seems that the choice between 24 was too difficult, or required too much time, so consumers skipped the jam altogether. However, this is probably an extreme case. There probably is such a thing as too much variety (especially when consumers are rushed), but if displays are well organized customers will probably easily navigate through the different options. Since consumers usually can choose more than one item, variety will rarely be intimidating.

\section{Timely Reminders}

McDonalds earned a good deal of unfavorable press for its "supersize" initiative in the early 2000s and the initiative was eventually dropped. But asking every customer if they would like to supersize their portions was a very effective way to influence customer behavior. Schwartz et al. (2012) use the same approach to encourage customers to downsize their portions. At a cooperating fast food restaurant, on certain days all customers were asked if they would like to save 200 calories by taking a half portion of their side dish. About one third of customers accepted the smaller portion, suggesting that many people are interested in opportunities to eat a little better, but they need to be reminded at the right time. A similar approach could be used to encourage customers to include vegetables as one of their side dishes.

\section{Default options}

The creation of appropriate defaults has been one of the most successful applications of behavioral economics to date. Successful applications of default options have led to increases in organ donation (Johnson \& Goldstein, 2003), retirement savings (Benartzi \& Thaler, 2007), selection of better insurance plans (Kahneman, Knetsch, \& Thaler, 1991), vaccination rates (Chapman et al., 2010), and college attendance (Bettinger et al., 2009).

There is some evidence that defaults can work in fast food settings. In 2006, the Disney Corporation decided to have apples served as the default in all kid's meals instead of French fries. Disney reports that the "overwhelming majority of families" accept the default option rather than choosing an alternative. It is worth noting, however, that a meal at Disney is not a routine meal. At cafeterias, produce could be automatically added as a side dish to meals, with customers (students) having to request an alternative.

Similarly, Just et al. (2007) have suggested that the Supplemental Nutrition Assistance Program (SNAP) could be changed so that the default allocation included a large proportion 
of produce and other healthy foods - this would preserve the individual's right to choose for themselves, although they would have to actively request an alternative allocation. This default option approach is likely to be more politically palatable than other policies such as the one proposed by Mayor Bloomberg in New York City which banned soda and other similar drinks from food assistance programs

\section{B. Incentive and Pricing Tools and Policies}

\section{Offer Strategic Discounts}

Discounts can provide incentives for increased consumption of fruits and vegetables. Jeffery et al. (1994) find that sales of fruit and salad increased threefold during a 3-week 50\% price-reduction period at a worksite cafeteria. French et al. (2004) find that a short-term intervention that lowered prices had a positive effect on fruit and vegetable consumption in school cafeterias.

These short-run changes in consumption can persist even after the prices return to their normal level. Mhurchu et al. (2010) conducted a six month intervention in which supermarket customers were randomly selected to receive either price discounts on food products, tailored nutrition education materials, or both. Supermarket customers who received price discounts experienced larger increases in their purchase of fruits and vegetables over the intervention period. Much of this increase in consumption was still present six months after the end of the intervention.

\section{Incentives}

There is a growing body of research that examines the impact of financial incentives in a variety of settings. Incentives influence behavior by turning the intangible benefits of behaviors, which influence long-run outcome, with tangible rewards. Incentives also help to counter the myopic preferences and impatience that causes individuals to forego long-run benefits in exchange for immediate rewards.

One successful incentive-based intervention is the Food Dudes program. This program was developed in Britain and is currently being used by all of the schools in Wales. It combines a small rewards program with a set of peer modeling videos that depict a set of super heroes who enjoy eating fruits and vegetables with short video clips of pop-stars who reinforce this message. There are a number of academic studies that examine the effects of this program (e.g., Horne et al., 2009; Greenhalgh et al., 2009; Lowe et al., 2004; Horne et al., 2004). These studies show that the program has a large effect on the amount of fruits and vegetables that children eat and that these effects are largest among the children who had the lowest levels of fruit and vegetable consumption prior to the start of the program.

One of the most prominent concerns about providing incentives is the degree to which providing rewards crowds out intrinsic motivation (Lepper, Greene, \& Nisbett, 1973; Deci, 1975). The primary concern is that a rewards program will actually cause children to eat even less fruits and vegetables once the rewards are discontinued. However, a recent study (Cooke et al., 2011) provides evidence that children actually acquire food preferences as they 
repeatedly try certain items. As such, short-term rewards may actually help children acquire a preference for fruits and vegetables, such that short-term rewards produce a long-run effect on consumption.

\section{Social rewards}

In addition to monetary rewards it is also possible to incentivize the consumption of fruits and vegetables through the use of social rewards or verbal praise. In their study of a group of children in the UK, Cooke et al. (2011) randomly assign children to receive either a tangible reward (a sticker) or verbal praise. They find that both the tangible reward and the social reward lead to an increase in consumption both during the intervention (which went for 15 days) as well as during follow-up periods (one and three months after the end of the intervention). Both the tangible reward and social reward had a similar effect on whether the children reported liking vegetables, which was about six times more likely than the control group. The tangible reward increased overall intake more, to about 58 grams from 15 grams. The social reward increased consumption to about 45 grams from a similar starting point. Unlike tangible (or monetary) rewards, social rewards may be more appropriately used in the home.

\section{Planning and Habit Tools and Policies}

\section{Pre-Commitment Tools}

There is some evidence that people will voluntarily pre-commit to choices to help themselves avoid procrastination or other temptations (Ariely \& Wertenbroch, 2002). To our knowledge, there are no large scale studies of pre-commitment to produce consumption (or to healthier eating more generally). But in many schools and organizations, the basic technology for this kind of program exists. Web tools can facilitate such programs. For example, the website SchoolMenu.com keeps online updates of lunch menus at thousands of schools nationwide. Through a site like this, parents (and children) may one day be able to order which items they will have for lunch in advance. Many work place websites may have similar functionality and could allow employees to pre-commit to the items they'll have for lunch.

On any given day at lunch, fruits and vegetables compete for attention with other less-healthy side dishes. If food decisions are made in the moment, then consumers are likely to choose the unhealthy option each day and decide that they will chose the more healthy items in the future. However, if decisions are made in advance, possibly with all of the decisions for the entire week made at the same time, then individuals will be able to pre-commit to healthy choices, and not be driven by the immediate impulse each day to take the less healthy options.

\section{Facilitate preference change}

The tools mentioned thus far address opportunities to get people to choose to eat more fruits and vegetables. But is there anything that can be done to get them to like these items more? Studies of taste change generally show that introducing new flavors with currently liked flavors increases the rate of adoption. 
Some studies have attempted to simply hide the taste of veggies by serving them in a puree. For example, Spill et al. (2011) served daycare children meals that were manipulated to different degrees through the addition of vegetable puree in foods like zucchini bread, pasta and sauce, and chicken noodle casserole. The key comparison is between standard servings and servings that were reduced in energy density by 25\% through the addition of puree. Across 3 meals and a snack, the daily vegetable intake increased significantly by $73 \mathrm{~g}$ (73\%). Children ate similar weights of food across conditions; thus, the daily energy intake decreased by $142 \mathrm{kcal}$ (12\%). And children rated their liking of the foods similarly across conditions.

\section{Simple Tracking Tools}

Almost all weight loss programs involve some kind of food tracking, often at the level of calorie tracking. The availability of mobile and online tools has led to a proliferation of personal tracking tools. For example, Keas is one company that allows people to track their compliance with very simple behaviors (e.g., did you eat 5 servings of fruit and vegetables yesterday?), and to share their reports with friends and family.

The difference between detailed and simple tracking may reflect a difference in the intended outcome. People who want to do detailed tracking are often interested in looking at trends over time so that they can see their own progress, or perhaps even discover hidden patterns in their own behavior. The main advantage of simple tracking, on the other hand, is that it just keeps a person on track. It is a small daily reminder that you are trying to change or keep up a particular behavior. You might want to look back and see how well you have done over time, but the main purpose is just the daily reminder.

\section{Appropriate nutritional labeling}

Calorie labeling has recently been introduced on restaurant menus in some US jurisdictions and has been mandated nationally under the Affordable Care Act. Studies to date have shown that the effects are modest at best, although longer term effects may be expected. The fact that effects are modest has led some behavioral economists to argue that overeating is not a result of lack of information, but rather, is due to a lack of self-control (Loewenstein, 2011; Schwartz et al., 2012).

Other types of labeling have been attempted that are more relevant for fruit and vegetable consumption. Thorndike et al. (2012) used a traffic light system in a large hospital cafeteria, which led to significant changes in product choice, although they do not specifically report changes in fruits and vegetables. Many grocery chains are introducing in-house or third party labeling schemes such as Guiding Stars developed by Hannaford, Healthy Ideas developed by Stop \& Shop/Giant, and NuVal developed by David Katz of Yale and used at several chains nationwide. In these schemes, fruits and vegetables are generally at the top of the scale, but the impact on consumer purchases has not yet been systematically studied. The traffic light system used by Thorndike et al. (2012) is somewhat unique in that it actually directs customers away from unhealthy choices. Many marketers are reluctant to do this, but it may 


\section{Macrothink}

Journal of Food Studies

ISSN 2166-1073

2012, Vol. 1, No. 1

be the most effective way to influence behavior. Such "negative" schemes need to be more systematically studied.

\section{Conclusion}

A new model of human behavior is becoming more widely accepted across the social sciences. This model assumes (based on years of empirical evidence) that consumers are not perfectly rational, and that marketers and policy makers who are concerned about consumer welfare need to manage the consumer offering to make it easier for consumers to make better choices. There is a dose of paternalism in this approach, but only a small dose. The approach does not generally recommend banning products or eliminating choice. Consumer freedom is preserved, but an understanding of the limitations in consumers' beliefs, preferences, and decisions leads the marketer or policy maker to devise displays, tools, incentives, and promotions that make it easier for consumers to make consumption decisions that support long term health. In this review 11 tools are outlined which can help to this end. Three general kinds of tools are described: tools for 1) displays and settings, 2) incentives and prices, and 3) planning and habits. For each specific tool, there is at least preliminary evidence of effectiveness, but, as noted throughout, much more empirical work needs to be done. Hopefully this review will encourage some of that research. 
Table 1. Summary of the behavioral economics toolkit.

\begin{tabular}{|c|c|c|}
\hline & Tool & Applications \\
\hline \multicolumn{3}{|c|}{ A. Display and Setting Tools and Policies } \\
\hline 1 & Prominence and Convenience & $\begin{array}{l}\text { There are many opportunities to make } \\
\text { produce more visible and prominent in } \\
\text { cafeterias, grocery stores, and homes. } \\
\text { Single servings have increased in } \\
\text { availability, but there is probably still latent } \\
\text { demand. }\end{array}$ \\
\hline 2 & Increase Variety & $\begin{array}{l}\text { At school and at home, kids will eat more } \\
\text { when there are more options to choose from. }\end{array}$ \\
\hline 3 & Timely Reminders & $\begin{array}{l}\text { Timely reminders can increase healthy } \\
\text { consumption in restaurants and cafeterias. }\end{array}$ \\
\hline 4 & Default Options & $\begin{array}{l}\text { This has been a powerful tool in savings and } \\
\text { retirement studies and there have been a few } \\
\text { studies in food domains. }\end{array}$ \\
\hline \multicolumn{3}{|c|}{ B. Incentive and Pricing Tools and Policies } \\
\hline 5 & Offer Strategic Discounts & $\begin{array}{l}\text { Short-term discounts can lead to long-run } \\
\text { increases in purchases. }\end{array}$ \\
\hline 6 & Incentives & $\begin{array}{l}\text { Tangible rewards can increase consumption } \\
\text { of fruits and vegetables. }\end{array}$ \\
\hline 7 & Social Rewards & $\begin{array}{l}\text { Praise for eating vegetables increases } \\
\text { consumption among small children. }\end{array}$ \\
\hline \multicolumn{3}{|c|}{ C. Planning and Habit Tools and Policies } \\
\hline 8 & Pre-Commitment Tools & $\begin{array}{l}\text { People eat healthier when they pre-commit to } \\
\text { meals, and more tools are providing } \\
\text { opportunities to do so. }\end{array}$ \\
\hline 9 & Facilitate Preference Change & $\begin{array}{l}\text { Children acquire a preference for fruits and } \\
\text { vegetables after repeatedly trying these } \\
\text { items. }\end{array}$ \\
\hline 10 & Simple Tracking Tools & $\begin{array}{l}\text { Most tracking tools are too complex for } \\
\text { sustained use. Simple tracking tools help } \\
\text { people achieve goals. }\end{array}$ \\
\hline 11 & Appropriate Nutritional Labeling & $\begin{array}{l}\text { Many third party labeling systems are being } \\
\text { introduced in supermarkets. }\end{array}$ \\
\hline
\end{tabular}

\section{References}

Ariely, D., \& Wertenbroch, K. (2002). Procrastination, deadlines and performance. Psychological Science, 13(3), 219-224. http://dx.doi.org/10.1111/1467-9280.00441

Ausubel, L. M. (1999). Adverse selection in the credit card market. Manuscript, University of Maryland. 
Bandoni, D.H., Sarno, F., Jaime P.C. (2011). Impact of an intervention on the availability and consumption of fruits and vegetables in the workplace. Public Health Nutrition, 14(6), 975-81. http://dx.doi.org/10.1017/S1368980010003460

Barber, B.M. and Odean T. (2002). Trading is hazardous to your wealth: the common stock investment performance of individual investors. The Journal of Finance, 55(2), 773-806. http://dx.doi.org/10.1111/0022-1082.00226

Benartzi, S., \& Thaler, R. H. (2007). Heuristics and biases in retirement savings behavior. Journal of Economic Perspectives, 21(3), 81-104. http://dx.doi.org/10.1257/jep.21.3.81

Bettinger, E. P., Long, B. T., Oreopoulos, P., \& Sanbonmatsu, L. (2009). The role of simplification and information in college decisions: Results from the H\&R Block FAFSA experiment. National Bureau of Economic Research Working Paper Series, No. 15361. Retrieved from http://www.nber.org/papers/w15361

Bucher, T., van der Horst, K., \& Siegrist, M. (2011). Improvement of meal composition by vegetable variety. Public Health Nutrition, 1(1), 1-7.

Camerer, C. \& Lovallo, D. (1999). Overconfidence and excess entry: An experimental approach. The American Economic Review, 89(1), pp.306-318. http://dx.doi.org/10.1257/aer.89.1.306

CDC. (2009). Majority of Americans not meeting recommendations for fruit and vegetable consumption. CDC Press Release. Available at: http://www.cdc.gov/media/pressrel/2009/r090929.htm.

Chandon, P. \& Wansink, P. (2011). Is food marketing making us fat? A multi-disciplinary review. INSEAD.

Chapman, G., Li, M., Colby, H., \& Yoon, H. (2010). Opting in vs opting out of influenza vaccination. Journal of the American Medical Association, 304(1), 41. http://dx.doi.org/10.1001/jama.2010.892

Choi, J. J., Laibson, D., Madrian, B. C., Metrick, A. (2003). Optimal defaults. American Economic Review, 92(2), 180-185. http://dx.doi.org/10.1257/000282803321947010

Cooke, L. J., Chambers, L. C., Anez, E. V., Croker, H. A., Boniface, D., Yeomans, M. R., \& Wardle, J. (2011). Eating for pleasure or profit: The effect of incentives on children's enjoyment of vegetables. Psychological Science, 22(2), 190-196. http://dx.doi.org/10.1177/0956797610394662

Cullen, K. W., Baranowski, T., Owens, E., Marsh, T., Rittenberry, L., \& de Moor, C. (2003). Availability, accessibility, and preferences for fruit, $100 \%$ fruit juice, and vegetables influence children's dietary behavior. Health Education and Behavior, 30(5), 615-626. http://dx.doi.org/10.1177/1090198103257254

Deci, E. L. (1975). Intrinsic Motivation. New York, NY, US: Plenum Press. http://dx.doi.org/10.1007/978-1-4613-4446-9 
DellaVigna, S. (2009). Psychology and economics: Evidence from the field. Journal of Economic Literature, 47(2), 315-372. http://dx.doi.org/10.1257/jel.47.2.315

Downs, J. S., Loewenstein, G., \& Wisdom, J. (2009). Strategies for promoting healthier food choices. American Economic Review, 99(2), 159-64. http://dx.doi.org/10.1257/aer.99.2.159

French, Simone A, \& Wechsler, H. (2004). School-based research and initiatives: Fruit and vegetable environment, policy, and pricing workshop. Preventive Medicine, 39 Suppl 2, S101-107. doi:10.1016/j.ypmed.2003.10.007

Greenhalgh, J., Dowey, A. J., Horne, P. J., Fergus Lowe, C., Griffiths, J. H., \& Whitaker, C. J. (2009). Positive- and negative peer modelling effects on young children's consumption of novel blue foods. Appetite, 52, 646-653. http://dx.doi.org/10.1016/j.appet.2009.02.016

Horne, P. J., Hardman, C. A., Lowe, C. F., Tapper, K., Le Noury, J., Madden, P., Patel, P., \& Doody, M. (2009). Increasing parental provision and children's consumption of lunchbox fruit and vegetables in Ireland: The Food Dudes intervention. European Journal of Clinical Nutrition, 63(5), 613-618. http://dx.doi.org/10.1038/ejcn.2008.34

Horne, P J, Tapper, K., Lowe, C. F., Hardman, C. A., Jackson, M. C., \& Woolner, J. (2004). Increasing children's fruit and vegetable consumption: A peer-modelling and rewards-based intervention. European Journal of Clinical Nutrition, 58(12), 1649-1660. http://dx.doi.org/10.1038/sj.ejcn.1602024

Iyengar, S. S., \& Lepper, M. R. (2000). When choice is demotivating: Can one desire too much of a good thing?. Journal of Personality and Social Psychology, 79(6), 995. http://dx.doi.org/10.1037/0022-3514.79.6.995

Jeffery, R. W., French, S. A., Raether, C., \& Baxter, J. E. (1994). An environmental intervention to increase fruit and salad purchases in a cafeteria. Preventive Medicine, 23(6), 788-792. http://dx.doi.org/10.1006/pmed.1994.1135

Johnson, E.J., \& Goldstein, D. (2003). Do defaults save lives? Science, 302(5649), 1338. http://dx.doi.org/10.1126/science.1091721

Just, D. R., Lund, J., \& Price, J. (2012). The role of variety in increasing the consumption of fruits and vegetables among children. Agricultural and Resource Economics Review, 41(1), 72-81.

Just, D. R., Mancino, L., \& Wansink, B. (2007). Could behavioral economics help improve diet quality for nutrition assistance program participants? USDA Economic Research Report.

Kahneman, D. (2003). A perspective on judgment and choice: Mapping bounded rationality. American Psychologist, 58(9), 697. http://dx.doi.org/10.1037/0003-066X.58.9.697

Kahneman, D. (2011). Thinking, Fast and Slow, Farrar, Straus and Giroux.

Kahneman, D., Knetsch, J. L., \& Thaler, R. H. (1991). Anomalies: The endowment effect, loss aversion, and status quo bias. The Journal of Economic Perspectives, 5(1), 193-206. 
Lepper, Mark R., Greene, D., \& Nisbett, R. E. (1973). Undermining children’s intrinsic interest with extrinsic reward: A test of the "overjustification” hypothesis. Journal of Personality and Social Psychology, 28(1), 129-137. http://dx.doi.org/10.1037/h0035519

Loewenstein, G. (2011). Confronting reality: Pitfalls of calorie posting. American Journal of Clinical Nutrition, 93(4), 679. http://dx.doi.org/10.3945/ajcn.111.012658

Lowe, C. F., Horne, P. J., Tapper, K., Bowdery, M., \& Egerton, C. (2004). Effects of a peer modelling and rewards-based intervention to increase fruit and vegetable consumption in children. European Journal of Clinical Nutrition, 58, 510-522. http://dx.doi.org/10.1038/sj.ejcn.1601838

Mhurchu, C. N., Blakely, T., Jiang, Y., Eyles, H. C., \& Rodgers, A. (2010). Effects of price discounts and tailored nutrition education on supermarket purchases: A randomized controlled trial. The American Journal of Clinical Nutrition, 91(3), 736-747. http://dx.doi.org/10.3945/ajcn.2009.28742

Moore, D. A., \& Healy, P. J. (2008). The trouble with overconfidence. Psychological Review, 115(2), 502. http://dx.doi.org/10.1037/0033-295X.115.2.502

Orszag, P. (2008). New Ideas about Human Behavior in Economics and Medicine. Congressional Budget Office. Retrieved from http://www.cbo.gov/ftpdocs/98xx/doc9887/10-16-Seidman_Lecture.pdf

Schwartz, J., Riis, J., Elbel, B., \& Ariel, D. (2012). Would you like to downsize that meal? Activating self-control is more effective than calorie labeling at reducing caloric consumption in fast-food meals. Health Affairs, 31 (2), 399-407. http://dx.doi.org/10.1377/hlthaff.2011.0224

Simonson, Itamar. (1990). "The effect of purchase quantity and timing on variety-seeking behavior. Journal of Marketing Research, 27, 150-162. http://dx.doi.org/10.2307/3172842

Spill, M. K., Birch, L. L., Roe, L. S., \& Rolls, B. J. (2011). Hiding vegetables to reduce energy density: an effective strategy to increase children's vegetable intake and reduce energy intake. American Journal of Clinical Nutrition, 94(3), 735-741. http://dx.doi.org/10.3945/ajcn.111.015206

Thaler, R.H., \& Benartzi, S. (2004). Save more tomorrow: Using behavioral economics to increase employee savings. Journal of Political Economy, 112, S164-S187. http://dx.doi.org/10.1086/380085

Thaler, Richard H., \& Sunstein, C. R. (2008). Nudge. Yale University Press.

Thorndike, A., Sonnenberg, L., Riis, J., Barraclough, S., \& Levy, D. (2012). A 2-phase labeling and choice architecture intervention to improve healthy food and beverage choices. American Journal of Public Health, 102(3), 527-533. http://dx.doi.org/10.2105/AJPH.2011.300391

Wansink, B. (2011, July). Mindless Eating. Presented at the Harvard Medical School, Boston, MA. 